\title{
LA TRISTA HISTÒRIA DEL CONVENT DE NOSTRA SENYORA DEL CARME DE VALLPARADÍS (TERRASSA)
}

\author{
JILL R. WEBSTER \\ S. Michael's College \\ University of Toronto (Canada)
}

L'Orde del Carme s'establl a Europa durant la primera meitat del segle XII!, i al final d'aquest mateix segle fundà convents a Lleida i Barcelona. Els primers frares de l'Orde del Carme havien d'enfrontar-se a una sèrie de problemes que no tenien els dominics o framenors. La principal dificultat, i podem dir que la més fonamental, era la recerca d'una identitat propia. Els carmelites havien tingut el seu origen a Mont Carmel, a Palestina, pero amb la caiguda de Jerusalem al final del segle XII deixaren el seu lloc d'origen i s'estengueren a Europa. La regla de Sant Albert, que s'establf entre el 1206 i 1214, fou un intent d'organitzar els diferents grups d'ermitans en un orde religios de tipus mendicant. Aixo no obstant, per a molts carmelites les arrels eremítiques eren més importants que la vida activa que, per a uns altres, tenia més valor. La dicotomia entre les tendencies contemplatives i les actives de l'Orde del Carme havia de causar inquietuds i cabories durant tota l'Edat Mitjana, especialment durant els segles XIV i XV quan la situació de l'Església provocà un desconcert entre els fidels i una inquietud general en tot el cristianisme occidental. Preocupat per la proliferació dels ordes religiosos de poca envergadura, el Concili de Lió del 1274 decidı de suprimir els menys viables com el dels Frares de Penitencia de Jesucrist, coneguts popularment com a frares del sac. Al mateix temps, decidiren deixar-ne continuar provisionalment uns altres, entre ells l'Orde de Nostra Senyora del Carme. Finalment, al voltant de l'any 1326, el papa Joan XXII estengué la bula Super Cathedram a tots els mendicants, i des d'aquell

"Anuario de Estudios Medievalea", 25 (1995) 
moment els carmelites tenien els mateixos privilegis i status que els dominics i franciscans.

La decisió del Concili semblava haver solucionat els problemes que tenia l'Orde sobre la seva identitat perque ja podien participar activament en els afers de la vida urbana. Pero el seu nou status feia que els frares del Carme, com els dominics i franciscans, haguessin d'afrontar l'antipatia del clergat secular que veia amb recel la popularitat dels mendicants que, per cert, els privaven d'una part del suport al qual estaven acostumats $i$, en conseqüencia, dels beneficis economics que aixठ suposava. Els frares del Carme tenien un problema més greu: la dicotomia interna de l'Orde que al segle XV, amb els problemes tant religiosos com socials, semblava adquirir una major importància. A més a més, el Cisma que havia dividit tota la cristiandat en camps adversos, els partidaris del papa de Roma i els que donaren suport al d'Aviny6, de la mateixa manera dividi l'Orde del Carme. La situació va durar més de vint anys i el fet que un dels papes fos aragonès tenia un relleu que no es podia menystenir; a continuacio veurem que el papa Luna va ser responsable de molts dels conflictes entre la nova fundació de Terrassa $i$ el convent del Carme de Barcelona.

És natural que aquesta divisio de l'Orde tingués repercussions en la vida espiritual i que impedís el normal desenvolupament de la missio dels frares. Evidentment, hi havia uns carmelites que es preocupaven per l'estat. de l'Orde, i més quan veien la trista trajectoria de les eleccions pontificals. Al capdavall, aconseguiren reunificar l'Orde l'any 1411 sota el priorat general de Fr. Joan Grossi, el mateix que havia estat general de la faccio avinyonesa ${ }^{1}$. Per als partidaris de Roma aquesta decisió no devia ser gaire grata $\mathrm{i}$ és interessant notar que algunes províncies no assistiren al Capítol General de Bolonya en el qual totes dues tendencies arribaren a un acord ${ }^{2}$. Entre els que no assistiren al Capitol, hi havia els representants de Catalunya on, cal suposar-ho, l'animositat contra els partidaris del papa romà era encara molt viva, $i$ on el provincial, Fr. Bernat de Riusec, era partidari de la faccio avinyonesa. Pels esdeveniments posteriors sembla que Fr. Bernat. no havia tingut cap interès a formar part d'un Capitol que tenia com a motiu principal la reunificacio de l'Orde. Finalment, per obediencia, i possiblement

\footnotetext{
'v. Joaquín SMET, Los carmelicas. Historia de la Orden del Cannen, Madrid, Biblioteca de Autores Cristianos, 1987, I, Los orígenes. En busca de la identidad, pp. 66, 97.

${ }^{2}$ SMET, Los Carmelitas, p. 66.
} 
contra voluntat seva, va haver 'd'acceptar la realitat; pero sembla ser que no va abandonar mai el seu amic, el papa Luna, Benet XIII. Aquest va viure al palau de Peníscola fins a la seva mort l'any 1424 , i, encara que dimitis del pontificat l'any 1415 , continuava animant els seus addictes a donar suport a la seva causa papal que ell considerava legitima.

Els esdeveniments del final del segle XIV i principi del XV devien ser desmoralitzadores per a molts frares, que no veien cap més solucio als problemes que l'abando de la vida activa en favor de la contemplativa. La fundacio del convent de Salgar, l'any 1404, era un exemple d'aquesta tendencia de retornar a la vida eremítica i seguir l'esperit dels primers frares carmelites $^{3}$. La decadencia de l'Església durant aquest perfode pertorbava els més devots $\mathrm{i}$ el retorn a una vida més simple $\mathrm{i}$ separada dels afers del món per a molts semblava l'única solucio. Per als franciscans, aquesta actitud resultà en una divisió de l'Orde en dos: conventuals i observants amb la fundacio del convent observant de Sant Esperit situat dins el terme municipal de Morvedre, el modern Sagunt (1404), precisament el mateix any de la fundació del convent carmelità de Salgarr. També, en alguns llocs, hi havia una renaixença cartoixana i l'exemple més destacat n'era el convent de la Vall de Crist, dotat l'any 1385 pel rei Martl, quan era primogenit, i el primer prior del qual fou Fr. Bonifaci Ferrer, germà del conegut Fr. Vicent de fama valencianas.

Fora de la Corona d'Arago, el mateix esperit de reforma es començà a notar, i al nord d'Itàlia els carmelites l'any 1413 fundaren el convent de Le Selve entre Florència i Pisa ${ }^{6}$. És possible que el convent de Terrassa fos una altra temptativa de reforma en terres catalanes $i$ un intent de retornar als origens eremítics, i és precisament la curiosa historia d'aquesta fundació que volem fer conèixer. La curta vida del convent, la seva posició ambigua i la

\footnotetext{
3v. Pau M. CASADEVALL, 50 Anys de la restauració de la provincia carmelitana de Catalunya. 1932-1982, Barcelona, Edicions Kàmel, 1986, p. 27.

4v. Pau M. CASADEvall, 50 anys de la restauració de la provincia carmelitana de Catalunya 1932-1982, Barcelona, Edicions Karmel, 1986, p. 27. Per a la fundació del primer convent observant a la Corona d'Aragó, Xelva, v. John R. H. MOORMAN, Medieval Franciscan Houses, New York, St. Bonaventure, 1983, p. 130 i per al convent de Sant Esperit, v. Jill R. WEBSTER, Franciscanismo de la reina de Aragón, Doria Maria de Luna (1396-14060, "Archivo Ibero-Americano", XLII (1982), p. 96, doc. 33, 21 octubre 1404.

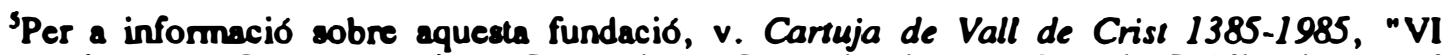
Centenario Actos Conmemorativos, Ponencias y Comunicaciones". Sogorb, Publicaciones del Centro de Estudios del Alto Palancia, 1985.
}

'SMET, Los carmelitas, pp. 116-117. 
manca de documentació no permeten arribar a conclusions definitives sobre el motiu dels fundadors. Aixo no obstant, podem dir amb certesa que l'Orde obligà el convent de Barcelona a tancar el de Terrassa després de pocs anys d'existencia. La decisió del capitol de Montpeller, del 1420, de destituir el prior de Terrassa del seu càrrec marcà la trajectoria del convent i el trist futur de Santa Maria del Carme de Vallparadis. Des d'aquest moment és evident que tingué problemes greus que els conventuals no es veien capaços de solucionar. La situació és complicada $i$, per tal de comprendre-la, cal recorrer als pocs documents notarials que resten a l'Arxiu Historic de Terrassa. Per la seva indole, apunts notarials $i$ alguna de les informacions no son prou explicatius per a fer altra cosa que conjecturar sobre la interpretacio correcta dels problemes que poguessin tenir els carmelites en aquell indret.

El convent del Carme a Terrassa va ser fundat en el mateix lloc abandonat pels cartoixans quan marxaren cap a Montalegre. El monestir cartoixà de Vallparadís fou establert a mitjan segle catorze a la propietat de la famnlia Centelles de Terrassa, i era un de tants monestirs que aquests monjos fundaren en aquella epoca a Catalunya i Valencia'. Tots tenien noms semblants i alguns, com Montalegre i Vall de Crist, varen tenir un paper de molta envergadura. Curiosament, i a diferencia dels altres, la vida del monestir cartoixà de Vallparadís de Terrassa va ser molt curta, possiblement perque hi havia uns altres monestirs proxims que el privaven del suport necessari per a desenvolupar-se. De totes maneres, l'Orde decidr vendre la propietat i, segons Josep Soler i Palet, els monjos abandonaren Terrassa l'any 1415, una data de la qual hem de discrepar perque els documents existents semblen suggerir que els cartoixans havien marxat de Vallparadís dos anys abans, o sigui al final del $1413^{8}$.

L'Orde del Carme, potser inspirada per l'esperit eremític, decidr comprar els terrenys del Castell de Vallparadís de Terrassa i fundar-hi un convent nou, filial del de Barcelona, en el mateix lloc que havien ocupat els cartoixans. La compra dels territoris fou realitzada per Fr. Bernat de Riusec, que residia al convent carmelita de Barcelona i la famnlia del qual havia tingut el seu origen al mas Riusec, de Terrassa, del qual parlarem més 87.

'Josep SOLER I PALET, Egara-Terrassa, Terrassa, Tallers grafics Joan Morall, 1928, p.

'SOLER I PALET, Egara-Terrassa, p. 87. 
endavant'. Fins ara, els historiadors dubtaven de l'efectivitat de la fundació, creient que només hi hagué una temptativa d'establir una casa a Terrassa ${ }^{10}$. La meva investigació dels llibres notarials de l'Arxiu Historic de Terrassa prova sense cap dubte que, per pocs anys, al començament del segle $X V$, el poble de Terrassa tingué un convent de frares del Carme.

El 13 de desembre de 1413, Fr. Bernat de Riusec, com a prior provincial (de la facció avinyonesa), efectuà la compra de Sant Jaume de Vallparadís, ubicat en el castell de Centelles a la parroquia de Sant Pere de Terrassa" ${ }^{11}$. En aquesta data, el batlle de la ciutat anuncia la compra dels terrenys pel mateix Fr. Bernat, mestre en teologia, prior provincial de Catalunya i vicari general de l'Orde del Carme. Escrit en catala, el text del document diu que fou "comprat en nom e a ops d'un novell monastir, lo qual se deu instituir en la dita casa sots invocació de la Verge Maria de la Vall de Sent Jacme del dit orde del Carma"12. La compra incloïa totes les possessions del monestir dels cartuixans, "homens e fembres, masos, censos, agents, demenys, rendes, terres, honors e possessions, molins, casals e ab tots altres [coses] del dit monastir de Sent Jacme de la Vall de Peradis de l'orde de Cartoixa". La compra fou anunciada a Barcelona per un perfode de trenta dies per deixar temps a la reflexió, per si algú estigués en contra de la venda. Segons el costum de l'época i d'acord amb la llei vigent, havien de passar trenta dies perque la compra fos legal. Si el comprador no havia pagat i signat el contracte durant aquell perfode, la venda es declarava nul.la. Si per alguna raó el venedor hi posava entrebancs i no signava, tampoc no s'efectuava la venda. La idea de tal provisió era d'evitar problemes de pagament o de canvi d'intenció per part d'un dels contractants. Sabem per les vendes posteriors que, entre les propietats que tenien els Carmelites amb

'Acta Capifulonum Generalium Ordinis Fratrum B.V. Mariae de Monte Carmelo, Roma, Apud Curiam Generalitiam, 1914, p. 160, n. 1.

${ }^{10} \mathrm{Cal}$ afegir-hi que els pares de Fr. Bemat, Maria i Nicolau, vivien a Barcelona. En Nicolau, mercader, va ser enterrat a la parròquia de Santa Maria del Pi, de Barcelona. V. Miguel Golobardes VILA, El convento del Carnen de Peralada, Barcelona, José Porter, 1953, p. 133, Testament de Francina, filla de Guillem Figuera de Perelada, 5 novembre, 1420. Agracixo aquí la gentilesa i l'ajuda del P. Pau Casadevall durant la preparació d'aquest estudi.

"SOLER I PALET, Egara-Terrassa, pp. 87-88. (Esmenta Fr. Bartomeu de Riusec, però el seu nom era Bemat i no Bartomeu).

12v. SOLER I PALET, Egara-Terrassa, pp. 87-88. L'original del document es troba a l'Arxiu Historic Comarcal de Terrassa, Llibre del Batlle, Joan Bosch, f. 49 r.-v. 13 desembre, 1413. Agraeiro aquí l'ajuda de l'arxiver de l'Arxiu Històric de Terrassa, Pere Puig i Ustrell, que busced infatigablement tots els documents utilitzats en aquest estudi. 
aquesta compra, quasi totes es trobaven a la parroquia de Sant Pere de Terrassa: les més interessants eren la probable casa familiar de Fr. Bernat de Riusec i les propietats que pertanyien a la famnia de Fr. Bernat de Far, un dels primers conventuals del nou convent del Carme de Terrassa ${ }^{13}$.

Evidentment, en aquest cas ningú s'oposà a la venda perque consta a L'Acta Capitulorum Generalium Ordinis Fratrum B.V. Mariae de Monte Carmelo que quatre dies més tard, o sia el 17 desembre de 1413, el papa Benet XIII comunicà la seva aprovació de la compra a un canonge de Barcelona perque ell ho fes saber a Fr. Bernat de Riusec ${ }^{14}$. L'Orde ja s'havia reunificat sota el general de tendencia avinyonesa, Fr. Joan Grossi, i alguns addictes de l'antipapa continuaven pertorbant la unitat aconseguida amb tanta dificultat. És curiós que la situació conflictiva del convent de Terrassa hagués pogut continuar durant tants anys sense resoldre's, o sense que el general de l'Orde hi intervingués, un fet que atribuïm a dues raons principals. Primerament, el provincial de Catalunya restava lleial al seu amic, l'antipapa, i tenia simpatía amb la posició de Fr. Jaume Berenguer de Terrassa; i el General de l'Orde, per la seva part, no volia prendre cap decisió que molestés Fr. Bernat de Riusec. D’aquesta manera, potser tant ell com Fr. Joan Grossi varen pensar que amb el temps la situació es resoldria per si mateixa.

L'Acta Capitulorum no mencionava la finalitat de la compra, potser perque a l'hora d'efectuar-la quedava incerta. De totes maneres, en decidir de fundar un convent a Terrassa, i d'acord amb la forma de pagament emprada pels ordes religiosos de l'època, els carmelites determinaren pagar a terminis la suma demanada per la compra. El primer pagament fou efectuat el dia 13 gener de 1414, aproximadament, i la resta de la quantitat un mes després, el 10 de febrer ${ }^{15}$. En aquella data sabem que els carmelites devien trenta lliures als cartoixans. Malauradament, no sabem quin percentatge aix representava del preu sencer. Seria normal que la segona paga representés una mínima part del preu de la propietat, i és possible que els frares

\footnotetext{
${ }^{13}$ AHC de Terrassa, Llibre del Batlle Felip dez Camer, 1429-1431, ff.45 v. 46 v. parlen del blat procedent del mas de Riusec que varen vendre els carmelites. Fem constar aquí el nom correcte del batlle, Felip dez Camer, i no Felip des Carres, com apareix al cataleg de l'Arxiu.

${ }^{14}$ v. nota 7.

${ }^{15}$ AHC de Terrassa, Llibre del batlle Joan Bosch, f. 49 r.-v. 13 desembre, 1413; f. 52 r.-v. 10 febrer, 1414. Calculant que havien de passar 30 dies des de la crida del batlle del 13 desembre, la primera paga devia efectuar-se a mitjan gener de 1414.
} 
paguessin un total de 130 lliures pel nou terreny. Dues setmanes després del primer anunci, n'hi havia un altre -encara que per l'estat molt deteriorat del document no se'n pugui llegir be el text-, que fa impossible saber si el convent ja s'havia establert o si s'anava preparant el terreny abans de prendre'n possessio ${ }^{16}$. Tot plegat, és evident que els frares no tardessin gaire a ocupar el Castell i nomenar el primer prior, Fr. Jaume Berenguer, perque el seu nom consta en un document del 7 de març de $1414^{17}$. El nom de Fr. Jaume com a prior de Barcelona es troba tambe dins el manual notarial de Julià Roure de Barcelona, l'octubre del i 412 i el març del 1413, $i$ hem de concloure que l'Orde el nomenà prior de Terrassa immediatament després de la compra del castell de Vallparadis ${ }^{18}$. És probable que des del principi Fr. Jaume tingués una certa independencia en els afers del convent afiliat al de Barcelona, ja que el provincial certament era amic seu. Aixo no obstant, podem dir també que el prior del convent de Barcelona intervingué en l'establiment de Santa Maria del Carme de Vallparadís de Terrassa $i$ en la seva vida accidentada. Els documents notarials suggereixen una possible manca d'enteniment entre el prior de Terrassa $i$ el prior de Barcelona, Fr. Jaume Pujades (escrit Pujada en tots aquests documents). És impossible dir amb certesa la causa d'aquest conflicte, pero no seria gaire arriscat suggerir que tenia a veure amb la insistencia del prior de Terrassa de continuar el seu suport per a Benet XIII, ja contra els manaments de l'Orde.

Nogensmenys, el 7 de març de 1414, Fr. Jaume Berenguer "com a prior" va demanar que els ciutadans respectessin la nova fundació i que la protegissin de qualsevol dany ${ }^{19}$. Era natural tambe que, durant els primers anys, el prior de Barcelona, Fr. Jaume Pujades, tingués interes a vigilar les activitats del nou convent, i encara més si tenia dubtes sobre l'enfocament espiritual de Fr. Jaume. Amb tots aquests tràmits preliminars, passaren uns quants mesos abans que els frares no poguessin ocupar el convent $i$, el 6 de març de 1414, per tal d'evitar perjudicis i danys per part dels ciutadans, Fr. Jaume Pujades (no Fr. Jaume Berenguer) nomenà el sots-batlle de la ciutat, Nicolau Vidal, teixidor de pany de lar?, com a procurador seu ${ }^{20}$. Aquest

\footnotetext{
${ }^{16}$ AHC de Terrasse, Llibre del batlle Joan Bosch, ff. 55 v.-56 r.

"AHC de Terrassa, Llibre del batlle Joan Bosch, f. 57 v.

"AC, Barcelona, Julid Roure, 1412-1413, 21 oct. 1412 i 31 març 1413.

${ }^{19}$ AHC de Terrassa, Llibre del batlle Joan Bosch, f. 57 v. document molt deteriorat.

${ }^{20} \mathrm{AHC}$ de Terrassa, Llibre del batlle Joan Bosch, f. $57 \mathrm{v}$.
} 
tenia l'obligacio d'ocupar-se de la nova propietat de Sant Jaume de Vallparadis, assegurant-se que no es presentessin contratemps durant l'epoca que el castell restés desocupat. Com que tenia les seves propies obligacions a Barcelona, Vidal no podia desplaçar-se a Terrassa per vigilar personalment els territoris. Aixl, el 14 de març, En Nicolau, complint les seves obligacions com a sots-batlle de Terrassa, i procurador de Fr. Jaume Pujades, va manar publicar un altre anunci ${ }^{21}$. La intencio era evitar que els ciutadans de Terrassa -dones, nens i nenes, o el bestiar, en qualsevol hora del dia o de la nit- trepitgessin la propietat anomenada Mas Viver, la casa que pertanyia als Mestres del Quadre de Casa o Castell dels Carmelites. Les infraccions serien castigades amb una multa de cinc sous.

Trobem un xic estrany el fet que els carmelites, una vegada pagada la compra, no ocupessin la casa; en altres situacions semblants, els frares acostumaven a residir en el lloc que havien comprat immediatament després de pagar la primera quantitat. Aqur notem una certa demora per part dels carmelites a poblar la nova propietat amb religiosos, malgrat la por que, si la deixaven buida, podien sorgir dificultats imprevistes. Sembla que la idea de fundar un convent a Terrassa nasqué d'un petit grup de frares, entre els quals es trobaven Fr. Bernat de Riusec i Fr. Bernat de Far, nadius de la ciutat $i$ addictes a l'antipapa, els quals, veient que els cartoixans abandonarien el castell de Sant Jaume de Vallparadís, cregueren que podien fundar un convent eremític carmelità. És possible que, amb aquesta intencio, anessin a trobar el venerable Bertran Nicolau, ciutadà adinerat de Barcelona i devot a Nostra Senyora del Carme, a fi de demanar-li els diners necessaris per a la compra. Sabem que Bertran Nicolau n'era el fundador i que uns quants anys més tard tornà a mostrar el seu arrelament a l'Orde donant una gran quantitat de diners al convent del Carme de Barcelona. Al voltant de l'any 1420, diposità 1555 lliures, 5 sous i 7 diners en una taula de canvi de Barcelona per a l'ús dels Carmelites ${ }^{22}$.

El motiu resta desconegut, pero essent l'any de la destitucio del seu càrrec de prior de Terrassa de Fr. Jaume Berenguer, ens preguntem si tenia quelcom a veure amb el convent de Santa Maria del Carme de Vallparadis.

\footnotetext{
${ }^{21}$ AHC de Temana, Llibre del batlle Joan Bosch, f. 59 v. p. 99 v.

${ }^{2} S$. CARDÚs, Historial del castell $i$ quadra del Vallparadis de Terrassa, Barcelona, 1936,
} 
Podia tractar-se d'una venda i no pas d'una donacio, però els documents existents no són prou explfcits per a poder endevinar-ho.

Sigui com vulgui, a partir d'aquell any el filial tornà a integrar-se molt més estrictament en l'estructura del convent de Barcelona. Fr. Bernat de Far, que l'any 1331 residia a Barcelona com a procurador de l'ex-convent de Terrassa, finalitzava la venda de la propietat de Vallparadís i, al mateix temps, servia l'hospital de Santa Creu de Barcelona ${ }^{23}$. El més interessant de tots, a part del prior, Fr. Jaume, era Fr. Bernat de Far, probablement de la famflia que tenia el mas de Far o el de Sa Castlania de la mateixa parroquia de Sant Pere. Seria interessant saber fins a quin punt ell o la seva famllia varen ser els animadors de la compra dels terrenys. Certament, va ser ell qui va intervenir en moltes transaccions fetes durant el perfode de liquidació dels bens del convent de Vallparadís i la persona amb més influencia a Terrassa. Com cal esperar, quan s'havien de liquidar els béns sempre hi havia entrebanes i, l'any 1426, Fr. Bernat, actuant en nom de Fr. Nadal Garriga, de la casa de Barcelona, havia de compareixer a Terrassa per explicar a Bartomeu Costa, canonge de la Seu de Barcelona i a Guillem Girona, de la mateixa ciutat, tots dos capitostos del Sagramental dels síndics i prohoms de la vila de Terrassa, el fet pel qual els homes del Sagramental no havien pagat contribucions de la talla; explicaren que no havien pagat perque no n'havien tret cap profit ${ }^{24}$. Es veu que els capitostos dels síndics i prohoms de la vila de Terrassa intentaven obligar els homes del Sagramental a pagar la talla. Fr. Bernat de Far i Fr. Nadal Garriga, fent ús de l'autoritat que els havia donat el rei, manaren i demanaren que aquells no

\footnotetext{
${ }^{23}$ AHC de Terrassa, Castell-cartoixa. Pergami sense classificar. Pcl scu interès el transcrivim a continuació, mantenint l'ortografia del document: Abans de l'inici del text, es troben les paraules "Jesus Christus": "Yo Frare Bernat Far de la horde de Madona Santa Maria del Carme de Bersalona, procuredor de la casse e castell qui solien ésser monestir de Cartuix he del Carme, e de l'espitall de Sente Creu de Bersalone, la qual casse e castell és en la perroquia de Sent Pera de Tarrasse he are és de Mosen Jofra de Sentmanat: atorch he regonech a vos, senyer en Ffrancesch, senyor del mas aq[u]ell que $m$ 'avets paguat per lo mas aq[u]ell per le tallenie una quarta de espelta e un fex de paya e una jove he una cistella e una carebasse, he per lo mas de Se Illa quasi cortere e mige de espelta de tallenie, he un fex de paya e una jove he una gallina de cens, e tres dine[r]s de cens. ltem: per Font Colloma me avets paguade una cortera de espelta de tallenia he un fex de paya he una jove, he per le queste de la monta[n]ya un sou 6 diners, i preu en diners 13 sous 19 diners, e axi com esta en veritat que'ls he aguts he rebuts, fa[i]g-vos lo present albara escrit de la inia ma pròpria cens cegcll, lo qual fou fet digmenge a 5 dies del mes de octobre en l'any XXXII lo qual cens desus dit és per l'any de XXXI." Al peu del foli es troba "Francesch" $i$, al darrera del pergami, "Franciscus Valls de Vilella de Santa Maria de Caldes de Muntbuy".

${ }^{24}$ AHC de Terrassa, Llibre del batlle, Felip dez Camer. 1425, f. 43 v, 13 maig, 1426.
} 
cobressin res de la dita quadra i que tampoc no procedissin contra seu. Sense tenir tota la correspondencia sobre el cas és difícil saber per què els dos carmelites tenien tanta autoritat, perd creiem possible que ells, conscients que el rei els protegia $\mathrm{i}$ que els ordes mendicants no havien de pagar impostos. l'haguessin assabentat del problema, i que a l'hora del document es trobaren prou segurs del seu suport per a defensar els drets dels homes de la quadra del Sagramental.

Els carmelites encara varen poder treure algún profit de les terres, després de clausurar el convent, venent el blat, el vi, la civada i altres productes, tant l'any 1429 com l'any 1431, alguns dels quals provenien del mas de Riusec ${ }^{25}$. L'últim document que parla de les quantitats rebudes de productes i terres és del 23 d'agost de 1431 i es tracta de 33 sous de tern de Barcelona que han de rebre d'Antoni Fabra del mas de Vinyals, de la parroquia de Sant Pere de Terrassa ${ }^{26}$. Alguns familiars de Fr. Bernat de Far vivien al mas de Sa Castlania, a la parroquia de Santa Maria de Terrassa, uns dibuixos del qual es troben al llibre de Cardús $i$, abans que els carmelites no marxessin de la vila, sembla que havien rebut censals sobre el mas que potser van adquirir quan varen morir els pares de Fr. Bernat ${ }^{27}$. De totes maneres, l'any 1321, Guillem de Far, possiblement el germà de Fr. Bernat, ja havia adquirit el mas de Sa Castlania, pagant els aniversaris a

\footnotetext{
${ }^{25}$ AHC de Terrassa, Llibre del batlle, Felip dez Camer. 1425, f. 56 v: el blat del mas de Sant Cristòfor, 4 juliol, 1426; f. 106 v: les olives i altres productes del mas Ses Oliveres en la parróquia de Sant Pere de Terrassa, 19 octubre, 1426; f. 116 r: civada al preu de 5 sous per quartera que Fr. Bemat de Far havia penyorat a casa de Gabriel Salarch. El saig dona 10 dies per a redimir-la, 20 novembre, 1426; f. 116 r. (document 2): vi de la quadra a un preu de 8 sous per "pannora", i un total de 10 "pannores". Tambe 10 dies donats per a redimir-la, 20 novembre, 1426; Llibre del balle, Fermí Rovira, 1427-1429, f. 19 r: "in encantu publico" civada a 5 sous per quartera que havia penyorat a casa de Bemat Sa Torra de Terrassa. 10 dies donats per a redimir-la, 24 septembre, 1427; f. 19 r (document 2): igual peró penyorat a casa de Cristòfor Aimeric de Terrasa. Fr. Bemat de Far tenia fins al diumenge següent per a redimir-la, 24 setembre, 1427; Llibre del ballle, Felip dez Camer, 1429-1431, ff. 45 v 46 r: blat del mas de Riusec i blat d'altres terres que tenien els Carmelites, 14 juliol, 1429; Llibre del Batlle-Felip dez Camer, 1431-1432, foli sense número: blat de propietats carmelites, 3 juliol, 1431.

${ }^{26}$ AHC de Terrassa, Llibre del batlle, Felip dez Camer, 1431-1432, foli sense número; el document és tan deteriorat que és difícil saber els detalls d'aquest pagament que, però, ha de ser liquidat abans del maig del 1432, 23 d'agost 1431.

${ }^{27}$ AHC de Terrassa, Batllia, Processos 1427-1430, 14 juny 1430, referint-se al difunt Guillem Far, del mas de Sa Castlania. Es tracta d'un deute de 18 florins a favor de la filla del difunt, Violant, dona de Francesc Nugans del mas de Far en la parróquia de Sant Pere de Terrassa.
} 
Santa Maria de Terrassa de l'Orde de Sant Rulf (Agustins), evidentment perque els Carmelites havien començat a tancar el convent de Terrassa ${ }^{23}$.

La vida dels carmelites no era gens facil durant les primeres decades del segle XV. Havien d'afrontar els conflictes que comportava el Cisma, la reunificació de l'Orde i la ubicació dels convents de Salgar, Terrassa i Vic. Pero mentre que, a Salgar i Vic, els problemes semblaven solucionar-se tranquil.lament, a Terrassa arribaren a ser cada vegada més dificils de resoldre. Sis anys després de fundar-se el corivent, el General de l'Orde censurà per desobediencia el Prior $\mathrm{i}$ els conventuals que residien al nou convent ${ }^{29}$. Al Capitol general de Montpeller del 26 maig de 1420, el General, Fr. Joan Grossi, havia demanat la dimissio de Fr. Jaume Berenguer com a prior del convent de Terrassa. És evident que aquesta decisió es va prendre després de consultar, potser diverses vegades, amb el prior de Barcelona, Fr. Jaume Pujades, sobre el comportament de Fr. Jaume Berenguer $i$ dels frares del convent de Terrassa $i$, sobretot, perque amb la reunificació de l'Orde l'obediencia de tots els convents era molt necessària per al futur desenvolupament de la missió carmelitana. Sembla que Fr. Jaume Pujades havia intentat corregir Fr. Jaume Berenguer, perd que aquest havia resistit totes les pressions per fer-li fer obediencia al General, al Provincial $i$ al Prior de Barcelona ${ }^{30}$. Igualment, podria ser que les relacions poc cordials entre Fr. Jaume Berenguer i Fr. Jaume Pujades, el prior de Barcelona, tinguessin l'origen en els problemes del Cisma. L'únic recurs que tenia Fr. Jaume Pujades era el del Capitol General, sobretot perque Fr. Jaume Berenguer tenia el suport dels altres conventuals de Terrassa. Certament, Fr. Jaume Pujades es sentia responsable del benestar del nou convent perque era filial del de Barcelona, i no ha de sorprendre que, finalment, hagués d'actuar en contra de Fr. Jaume Berenguer. Creiem que, en aquest cas, hi havia unes circumstàncies especials, com per exemple l'amistat entre Fr. Bernat de Riusec i Fr. Jaume Berenguer i la vinculació de tots dos al Papa Luna. Segons l'Acta Capitulorum Generalium, Fr. Pere Just era provincial de Catalunya (de la faccio romana?) l'an; 1411 pero, sense que hi hagues un

\footnotetext{
${ }^{23}$ AHC de Terrassa, Pergamí VI-60, de l'l d'agost, 1421, Guillem de Far de la parrìquia de Sant Pere paga aniversaris a Santa Maria de Terrassa, pertanyent a l'orde de Sant Rulf.

${ }^{29}$ AHC de Terrassa, Notari Joan Bertran, Manuale, 1419-1421, f. 58 r, 6 juliol, 1420.

${ }^{*}$ AHC de Terrassa, Notari Joan Bertran, Manuale, 1419-1421, ff. 56 r.58 r, 6 juliol, 1420 (dos documents). El notari, Ramon Mora, hi intervingué el 20 de juny, 1420, però no tenim aquest document.
} 
altre capitol general, l'any de la compra de Vallparadís (1413) l'Acta menciona Fr. Bernat de Riusec com a provincial ${ }^{31}$. L'any 1416 el Capitol General de Banyuls (província de Narbona) no va nomenar cap frare provincial de Catalunya i sembla que Fr. Bernat tingué el càrrec fins al 1420. Encara que, com a provincial, ell tenia l'obligació de disciplinar el prior de Terrassa, si aquest no feia cas del prior de Barcelona per raons d'antipatia personal, és molt probable que Fr. Bernat preferís evitar la decisió violenta de destituir el prior a qui ell mateix havia donat suport l'any 1413. Al capitol general del 1420, Fr. Joan Grossi va nomenar Fr. Bernat soci seu, probablement per allunyar-lo del conflicte de Terrassa, i Fr. Jaume Pujades, definidor de Catalunya ${ }^{32}$. Aquesta decisio del General sembla confirmar la nostra opinio que Fr. Bernat de Riusec es trobava en una situació molt delicada i preferia distanciar-se d'una decisió que ell, per raons d'amistat $\mathrm{i}$ vinculacio durant el Cisma, no podia aprovar.

Aixi, el 4 juliol de 1420, en presencia del notari Joan Bertran, el capellà de Sabadell, Pere Serra, Francesc Sastre de Terrassa i Ramon Mora, causídic de Barcelona i procurador del prior provincial Fr. Jaume Pujades, fou llegit un document que comunicava la decisio del capitol general a Fr. Jaume Berenguer $i$ als frares del convent de Terrassa ${ }^{33}$. En presentar-se davant el convent aquests delegats del provincial, trobaren les portes tancades i sembla que ningú no volgué obrir-les. Sens dubte, tots els frares s'havien assabentat del contingut del document i de la decisió del General de l'Orde. Els representants del prior de Barcelona insistiren que obrissin la porta, i finalment un frare decidr fer-ho. Dissortadament, tractant-se d'apunts del notari, el text sencer no apareix al manual notarial, i aixo fa impossible assabentar-se de tot el contingut del document enviat pel General de l'Orde. No dubtem que fou escrit amb tota la força disciplinària que tenia a la seva disposicio Fr. Joan Grossi. Hi queden l'incipit i la referencia a la data del capítol del 26 maig amb l'anotació que es tractava de comunicar a Fr. Jaume Berenguer la decisio del General. Explica molt clarament que Fr. Jaume i els seus frares han d'obeir "sub pena rebellionis" perque la seva rebel.lio, segons el document, anava contra el Papa, el General de l'Orde i el prior de

\footnotetext{
${ }^{31}$ Fr. Gabriel Wessels, Acla Capitulorum Generalium Ordinis Fratrum B.V. Mariae de Monte Carmelo, Romae, Apud Curiam Generalitiam, 1914, I, p. 139.

32. WESSELS, Acla, I, p. 160.

33. note 29.
} 
Barcelona. Aqui hi ha una confusio, perque no hi ha cap referencia al càrrec de Fr. Jaume Pujades; el document l'anomena prior de Barcelona perd, de fet, el prior del convent de Barcelona, l'any 1420, era Fr. Joan Xifre o Sifredi, i Fr. Jaume era definidor de Catalunya ${ }^{34}$. Aquell mateix dia, el 6 de juliol de 1420, Fr. Jaume Berenguer deu la seva resposta a la comunicacio de Fr. Jaume Pujades i del procurador, Ramon Mora, donant la seva conformitat al manament del General, Fr. Joan Grossis ${ }^{35}$. No tenim el text de la resposta de Fr. Jaume Berenguer, pero creiem que l'episodi de la porta confirma el disgust que sentien el prior de Terrassa $i$ els seus companys. Tots els documents posteriors, amb una sola excepcio, el qualifiquen com a olim prior, o sia "el que fou prior ${ }^{\text {"36 }}$. Molt a desgrat seu, Fr. Jaume s'havia vist obligat a complir la decisio del Capitol General de Montpeller i traslladar-se al convent de Peralada quan va marxar de Terrassa. Pel que sabem de la seva vida posterior, continuava a Peralada, d'on era cadiu, i visqué alli fins al 1435 , i potser encara alguns anys més ${ }^{37}$.

No obstant aixo i llegint entre ratlles, creiem que Fr. Jaume Pujades havia donat una gran oportunitat perque el prior de Terrassa es penedís de la seva intransigencia; havien passat quasi deu anys des de la reunificacio de l'Orde. El papa Luna, que potser va ser la causa de les dificultats, no morr fins el $1424 \mathrm{i}$, fins a la seva mort, hi havia molta gent de la Corona d'Arago que continuava donant-li suport, $i$ aix 6 era causa de problemes de lleialtat $i$ d'addiccic al papa de Roma. Es podria comptar Fr. Jaume Berenguer entre ells? No ho sabem, pero ho creiem molt probable, ates el ressentiment que

\footnotetext{
34. Pau M. CASADEVALL, Set-cents anys de presència dels carmelites a Barcelona (12921992) Breu noticia, Barcelona, Ed. Pares Carmelites, 1992, p. 83, i nota 32. Fr. Jaume Pujades assumi la regència del convent de Terrassa després de la destitució de Fr. Jaume Berenguer.

${ }^{35}$ v. Notari Joan Bertran, Manuale, 1419-1421, f. 58 v.

${ }^{36}$ AHC de Terrassa, Notari Joan Bertran, Manuale 1421-1422, f. 68 r: Bemat Vidal, procurador de l'hospital de Terrassa, acusa rebuda a Fr. Jaume Berenguer, mestre en sagrada eacritura, "olim prior" de censos, diners i béns que l'ex-prior devia a l'hospital; f. 69 r: Fr. Jaume Berenguer, "olim prior", acusa rebuda a Guillem de Muntanyans, miles, de 38 lliures de Barcelona de tern, el preu del mas anomenat "Lo mas del molí sobira", situat dins la quadra del monestir de Santa Maria del Carme a la parroquia de Sant Pere de Terrassa, 3 març, 1422. Aquest mas pertanyia a Bemat Berenguer d'Avinyonet, de la diòcesi de Girona.

${ }^{37} v$. GOLOBARDES VILA, El convent, pp. 133 i 139. Es interessant notar que els dos amics, Fr. Jaume Berenguer i Fr. Bemal de Riusec, se n'havien tomat a viure al mateix convent, i que tots dos eren mamessors del testament de la germana de Jaume Berenguer, Francina. Com que aqueata era filla de Guillem Figuera, suposem que tant Jaume com ella nasqueren de la mateixa mare, peró no del mateix pare.
} 
sentia per la seva forçada dimissió del càrrec de prior i per la seva obstinada vinculació a Benet XIII. Sigui com vulgui, la destitució del prior debilità el convent de Santa Maria del Carme de Vallparadis i presagia la cloenda d'un episodi poc il.lustre per als frares del Carme de Barcelona.

A continuacio, donem un resum dels documents existents per a subratllar la cronologia dels fets que, en aquest cas, resulta tan important. Com ja indicarem al principi d'aquest estudi, no hem trobat cap més documentació que la conservada a l'Arxiu Historic de Terrassa. Els registres de cancelleria dels reis de la Corona d'Arago, tan rics per a altres coses, no esmenten aquest convent de Terrassa. Els Acta Capitulorum registren la compra del terreny a Terrassa i la temptativa de fundar el convent, pero no parlen de l'episodi malaurat per a l'Orde. En total, hem de comptar amb uns cinquanta documents, alguns dels quals no tenen més que un incipit o una data amb l'anotació que l'escrit no s'efectués. Ja hem fet referència als documents de compra de la casa $\mathrm{i}$ ara parlarem dels pocs documents que es refereixen als anys anteriors a la destitucio de Fr. Jaume Berenguer.

Pel novembre del 1414, Fr. Jaume Berenguer, mestre en Sagrada Escriptura i prior, i Pere de Vallseca, de Barcelona, concediren els censos d'uns camps en franc alou, anomenats "de les Centelles", a un resident de la parroquia de Sant Joan, per 11 sous de Barcelona, que s'havien de pagar cada any per $\mathrm{Nadal}^{33}$. Uns quants dies més tard, trobem Fr. Jaume com a prior, amb Fr. Montserrat de Puigalt, Fr. Antoni Adrover i Fr. Bernat de Far, els quals, amb Pere de Vallseca de Barcelona, establiren un cens en emfiteusi relacionat amb una propietat anomenada "Argamirts", situada a les muntanyes de Les Garrigues, per 8 sous que s'havien de pagar cada any per Nadal, a partir de la data del document ${ }^{39}$. El dia següent, fan el mateix amb una altra casa "Cabanyes", per 22 sous d'entrada el proxim Nadal; i, el 26 febrer de 1415, en un capítol conventual al qual assistiren tots els frares del convent de Terrassa, tornaren una sèrie de productes del mas de Sa Castlania a Bartolomeu Barbe, de la parroquia de Sant Julia ${ }^{40}$. En aquell capítol eren presents Fr. Jaume Berenguer, prior, Fr. Montserrat de Puigalt, Fr. Antoni

\footnotetext{
"Ms. "Comtelles", perì creiem que hauria d'Éser "Centelles", v. AHC de Terrassa, Notari Lluis Agusti, Manuale 1413-1415, f. 82 r.

${ }^{39}$ AHC de Terrassa, Notari Lluis Agustí, Manuale, 1413-1415, f. 86 r, 4 desembre, 1414. Hi consta al foli 85 v un altre document sobre la qüestió de propietats, peró com que és molt deteriorat no podem llegir-ne el nom. El capitol es trobe al foli $96 \mathrm{v}$ del mateix manual.

${ }^{\infty}$ AHC de Terressa, Notari Lluís Agusti, Manuale, 1411-1413, f. 87 r.
} 
Adrover, Fr. Miquel Massot i Fr. Bernat de Far, un total de cinc frares. El territori que pertanyia als cartoixans devia cobrir una àrea molt gran i es interessant remarcar que tots els documents, amb l'excepcio del que tracta de la dimissio de Fr. Jaume Berenguer, es relacionen amb les propietats que regien els carmelites. L'origen cartoixà dels territoris queda ben evident $i$ els documents semblen molt més normals per als habitants originaris de Vallparadis que no per als frares que acabaven de comprar-los. Aquesta realitat ens fa preguntar, una vegada més, quin motiu tenien els carmelites de comprar territoris tan extensos per a fer un convent eremític? Les conclusions tampoc poden ser definitives per manca de documentacio, pero és possible que, assabentat del desig d'alguns frares de viure fora de la ciutat i dedicar-se a la vida contemplativa, el fundador Bertran Nicolau els oferis els diners per a comprar el castell de Vallparadís. En aquest cas, hauria estat dificil rebutjar l'oferta tan generosa i d'alls, potser, varen néixer els conflictes que tenien Fr. Jaume Berenguer i Fr. Jaume Pujades, que vivien tots dos en aquell moment al convent de Barcelona. El castell amb les seves pertinences responia molt bé a les necessitats dels cartoixans, pero per als carmelites no podia fer més que produir una sèrie de cabories. La seva missio era diferent, mendicant $i$ concentrada en la població urbana, i no tenien ni l'experiencia ni els recursos financers per a mantenir propietats com la de Vallparadis de Terrassa.

La destitució del prior complicava una situacio que ja s'havia fet insostenible tant per l'actitud dels frares com per les despeses de la propietat, que no podien pagar. És evident que Fr. Jaume intentava liquidar els deutes i pagar els creditors abans de deixar per sempre el seu càrrec, perd no va poder fer-ho, i va ser Fr. Bernat de Far que va haver d'encarregar-se de la liquidació $\mathrm{i}$ venda de la propietat. En un document del 22 de febrer de 1422 , consta que el mateix Fr. Jaume Pujades, prior, havia afegit el priorat de Terrassa a les seves responsabilitats perd, per tal d'evitar els problemes que la seva absencia podia causar en un moment tant dificil per al convent, nomenà, com a sots-prior, Fr. Pere Aj iers ${ }^{41}$. Pel juliol del 1422, els frares varen vendre les rendes sobre unes propietats a Terrassa $i$, pel desembre del mateix any, o sia dos anys i mig després de la decisió del Capítol de Montpeller de reemplaçar Fr. Jaume per un altre, el mas dez Posal, una

${ }^{41}$ AHC de Termasa, Notari Joan Bertran, Manuale, 1421-1422, f. 122 r (falta el f. 121 v). 
propietat que tenien al Carrer Major ${ }^{\wedge 2}$. Aquesta venda la realitzà Fr. Romeu Broguart, deodarus, del convent del Carme de Terrassa.

Entre les possessions que tenien, hi havia uns molins $i$ algunes cases a la mateixa parroquia de Sant Pere de Terrassa, tots aquests, sense cap dubte, pertanyents als territoris adquirits amb la compra feta l'any 1413. El fet que Fr. Jaume Pujades assumis la regencia del convent de Terrassa, nomenant un sots-prior, per a ajudar-lo, indica la manca de viabilitat de Vallparadís i la intenció de l'Orde de liquidar els béns que tenien abans de marxar definitivament de Terrassa. Cap a l'any 1424, els documents, quan parlen del convent de Santa Maria del Carme, ja no hi afegeixen "de Vallparadís", pero la situació econòmica sembla haver-se deteriorat significativament. És possible que l'apostolat dels frares del Carme ja s'hagues acabat $i$ que els documents que hem trobat indiquin la fi d'una època poc profitosa per a l'Orde. Sigui com vulgui, la venda de les propietats va durar més temps i, per l'octubre del 1426, Fr. Nadal Garriga, aleshores prior del convent de Barcelona, s'encarregava de liquidar les propietats restants ${ }^{43}$. Moltes propietats ja no eren de gaire valor perque els carmelites no n'havien tingut cura. La venda del Mas de Ses Oulomares es va efectuar el 24 de novembre de 1426 i varen ser Fr. Llorens Liura, conventual del convent de Santa Maria del Carme de Terrassa i procurador del lector en teologia, i el prior de Barcelona, Fr. Joan Xifre (Xiferre en

aquests documents) de Vallparadís, aquells qui van substituir Fr. Bernat de Far en aquesta ocasio"s. Pere Vidal havia de pagar als frares i a l'Hospital de la Santa Creu de Barcelona un parell de capons i 9 sous 4 diners de tern de Barcelona, cada any, per Nadal. També havia de fer al mas sis "podades...batudes tot quot dicta domus vocate de Cartuxa habebit...una jovam...quintum de omnibus spletis quos Deus dederit in quadam pecia terre vocata La Clota"; pero la venda de les propietats arruïnades no cessava i el

\footnotetext{
${ }^{42}$ AHC de Terrassa, Notari Joan Bertran, Manuale, 1421-1422, f. 174, 5 juliol 1422. El document situa aquest mas dins la parroquia de Sant Pere de Terrassa.

${ }^{4}$ AHC de Terrassa, Notari Jaume Gili, Primum Manuale, 1426-1427, f. 61 v, un document que nomé té l'incipit; f. 65 r, 17 octubre, 1426: Pere Vidal de Terrassa rep la propietat arruinada de Ses Oulomares, a la parroquia de Sant Pere de Terrassa. Al marge, hi ha una nota del notari "vaccat quid est infre fimma cum per fratrem Bermardum de Faro".

"AHC de Terrassa, Notari Jacme Gili, Manual de 1426-1427, ff. 74 r.-v. Suposem que aquest document confirina el del f. $65 \mathrm{r}$, del 17 d'octubre, segons el qual Pere Vidal accepta el mas de Sas Oulomares, i que ara estipulen les condicions del contracte. Te el mas en emfiteusi.
} 
"Mas dez Sa Costa", situat a les muntanyes de Les Garrigues, a la mateixa parroquia de Sant Pere, fou venut el 24 de novembre de $1426^{45}$. Altres cases arruïnades que vengueren els frares en aquesta epoca foren les que pertanyien als germans Font, Joan i Bartomeu, fills del difunt Bartomeu Font, de la parroquia de Sant Pere, bé que, en el moment de la venda, eren de la de Santa Eulalia ${ }^{46}$. També varen vendre el mas de "Ses Albaredes" en el districte de muntanyes de Puig Estevaa" La responsabilitat de Fr. Joan Xifre era evident, la de vendre tot el que podia abans que els frares abandonessin Terrassa ${ }^{48}$. Les propietats que els carmelites havien adquirit dels cartoixans es trobaven a la ribera del riu de Vallparadís, i consistien en cases de pages i terra de conreu. Els frares del Carme conreaven la terra i, fins $i$ tot, tenien bestiar. No sabem si el bestiar es limitava a una vaca o si aquesta va ser l'última cosa que van haver de vendre's, pero, l'any 1429, la varen vendre a Joan Ramoneda, del mas de Canyet, a la parroquia de Sant Pere de Terrassa ${ }^{49}$. Era de pell grisa o clara, $i$ el preu que n'obtingueren era de sis florins d'or d'Arago, una suma considerable perquè esperaven que la vaca tingués cria. El contracte de venda tenia unes condicions importants: que el comprador li donés bona pastura, en tingués força cura i no la vengués, ni que tampoc vengués la cria que pogués tenir sense obtenir el permis dels frares de Santa Maria del Carme del convent de Barcelona. Ens preguntem per que no la deixaren anar al venedor sense aquesta darrera condició que sería molt difícil de complir. Sembla que la vaca va ser l'última peça d'un trencaclosques que havia durat més de setze anys, sense donar cap resultat positiu.

\footnotetext{
${ }^{45}$ Les condicions de la venda del mas en emfiteusi són complicades $i$, per ordre de Fr. Nadal Garriga, mestre en Sagrada Escriptura i prior de Santa Maria del Carmc, de Barcclona, sembla que durant 30 dies "et ultra" l'assumpte devia anar a compte de Jaume Ça Torra, corredor públic de la vila de Terrassa, i que Vidal havia de pagar 30 norins d'or d'Aragó per la transacció.

${ }^{46}$ AHC de Terrassa, notari Jaume Gili, Secundum Manuale, 1427-1429, f. 102 r.

"AHC de Terrassa, foli solt, al Secundum manuale de Jaume Gili, 1427-1429, amb data de 10 septembre, 1429.

${ }^{40 f}$. WESSELS, Acta, I, p. 170 (1425): "Item ordinamus quod Conventus Terrasciae sit Conventus Barchinonae, et ordinamus quod expensae factae pro defensione Conventus Terrasciae per Fratrem Johannem Cifrerii solventur triginta una libr. IX s. per Conventum Barchinon". 1429.

${ }^{49}$ AHC de Terrassa, Jaume Gili, Secundum Manuale, 1427-1429, f. 166 r, 1 septembre,
} 
L'any 1432, Jofre de Sentmenat, autoritzat per l'hospital de la Santa Creu de Barcelona, comprà la propietat i posà fi a una epoca poc feliç per als carmelites de Terrassa. El castell de Vallparadís quedà en mans de la famflia Sentmenat fins al 1852, quan passà a la famflia Mauri que varen viure-hi fins aquest segle $e^{50}$. Avui dia és museu de l'Ajuntament de Terrassa, un fet ironic perquè, abans que Jofre comprés la propietat, el Consell $i$ Jurats de la Vila, reunits el 8 de desembre de 1427, ja acordaren comprar$\mathrm{la}^{51}$. Prengueren aquesta decisió després de moltes deliberacions, probablement iniciades l'any 1422, quan Fr. Bernat de Far i Fr. Pere Ayners assistiren a una reunió del Consell com a testimonis de l'Acta dels regidors de la Vilas ${ }^{52}$. Pel que es pot deduir, hi havia algun conflicte sobre la compra de la casa, potser per les complexes relacions entre el castell i les cases, molins i totes altres depèndencies del Sagramental, o per la intervenció de Jofre de Sentmenat o per no haver pagat les contribucions de talla. Les cabories del procurador, Fr. Bernat de Far, i del definidor $\mathrm{i}$ prior de Terrassa, Fr. Jaume Pujades, duraren molts anys fins que per $\mathrm{fi}$, varen poder vendre tota la propietat i les seves dependencies.

En conclusio, és evident que la compra dels territoris de Vallparadis i la fundació del convent de Santa Maria del Carme varen ser uns errors que varen costar cars a l'Orde, i especialment al convent del Carme de Barcelona. Hem de recordar, perd, que l'Orde patia uns anys de divisió $i$ decadencia, anys que potser es poden considerar de preparació per als canvis de la renaixença i que, sense cap dubte, dificultaren la vida dels carmelites. Els terrenys de Terrassa eren massa grans i massa complicats per a un orde que tenia força dificultats per a mantenir-se bé economicament. El convent de Salgar ocupava una àrea més petita i per aixd era més fácil mantenir-lo; aixo no obstant, la tendència eremítica mancava dels mitjans economics per continuar sostenint convents fora dels centres urbans. Fr. Bernat de Riusec, soci del General de l'Orde entre 1420 i 1425, ja d'edat avançada, degué anar a viure a Peralada fins que morl entre 1425 i 1434, sens dubte trist $i$

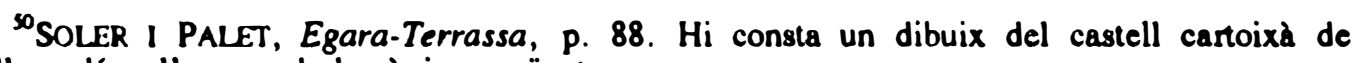
Vallparadís a l'anvers de la pàgina següent.

st AHC de Terrassa, Llibre de Consells de la Vila, 1422-1447, papers solts, f. 21 r, 8 desembre, 1427.

${ }^{5}$ AHC de Termase, Llibre de Consells de la Vila, 1422-1447, ff. 3 r -4 v, 24 novembre 1422. Es possible tambe que el conflicte sobre el pagament de la talla, de l'any 1426, fos una indicació de la necessitat de trobar un comprador per als terrenys dels carmelites.
} 
desil.lusionat amb l'ensorrada d'un somnis ${ }^{\text {s3 }}$ Mentrestant, sembla que Fr. Jaume Berenguer va continuar el seu apostolat a Perelada i que Fr. Bernat de Far va restar al convent de Barcelona, desenvolupant la seva feina que comprenia el càrrec de procurador de l'hospital de la Santa Creu de Barcelona ${ }^{s 4}$. El malaurat capitol de la fundació de Santa Maria del Carme de Vallparadis s'havia tancat, pero la seva historia suggereix que la dicotomia de l'Orde del Carme durant l'Edat Mitjana portava problemes espirituals i personals dins la província de Catalunya, conflictes que potser, per manca de documentacio, resten desapercebuts, o desconeguts.

\section{Relació dels conventuals de Santa Maria del CARME DE Vallparadís. 1414-1432}

1414. Fr. Jaume Berenguer, mestre en Sagrada Escriptura, prior, Fr. Montserrat de Puigalt, Fr. Antoni Adrover, Fr. Bernat de Far

1415. Fr. Jaume Berenguer, prior, Fr. Montserrat de Puigalt, Fr. Antoni Adrover, Fr. Miquel Massot i Fr. Bernat de Far.

1416. Fr. Jaume Berenguer, prior

1419. Fr. Jaume Berenguer, prior

1420. Fr. Jaume Pujades, mestre en sagrada escriptura, Barcelona, Fr.Jaume Berenguer, prior, Fr. Joan Xifre, prior, Barcelona.

1422. Fr. Jaume Pujades, mestre en Sagrada Escriptura, prior, Fr. Pere Ayners, sub-prior, Fr. Pere de Fuxo, sacrista, Fr. Bernat de Far, Fr. Romeu Broguart, "deodatus", Fr. Montserrat de Puigalt.

1423. (capitol) Fr. Jaume Pujades, prior, Fr. Antoni Barcel6, Fr. Montserrat de Puigalt, Fr. Pere de Fuxo, Fr. Joan Deuna, Fr. Andreu Marmenchs, Fr. Bernat Març[ol], Fr. Miquel de Puig, Fr. Bernat de Far, Fr. Bartolomeu Pons i Fr. Roderic de Vilamajor i de la casa de Barcelona Fr. Nadal Garriga, Fr. Llorens de Coll de Saus, Fr. Guillem dez Pla, Fr. Pere Ayners i Fr. Montserrat Puigalt (notem que aquests podien haver-se

\footnotetext{
${ }^{33}$ Ordenat sacendot el 18 de febrer de 1391 (ADB, Reg. Ordinacions 7, f. 119 v), és probable que tingués més de 50 anys quan mori.

${ }^{4} \mathrm{Fr}$. Jaume Berenguer va ser ordenat sacerdol el 15 de marc de 1402 (ADB, Reg. Ordinacions 8, f. 82 v) i Fr. Bemat de Far, el 12 de març de 1418 (ADB, Reg. Ordinacions 9, f. 11 r).
} 
traslladat de Terrassa a Barcelona quan Fr. Jaume Berenguer fou destituït del seu càrrec).

Des d'aquest moment, Fr. Bernat de Far continuava com a procurador de Santa Maria del Carme de Vallparadís mentre visqués al convent de Barcelona.

1426. Fr. Llorens Lliura.

\section{RÉSUMÉ}

L'Etablissement du couvent des Grands Carmes a Vallparadis, Terrassa, pendant l'année 1413 semble avoir éé une expérience malpensée par quelques frères qui avaient l'intention de faire retoumer l'Ordre la vie contemplative. Les seuls documents qui existent maintenant indiquent que l'expérience n'était pas très positive, réveillant les sentiments d'hostilité entre les frères de Terrassa et leurs superieurs dans la Province de Catalogne. L'experience ne dura pas plus de vingt ans, parce que l'Ordre vendit le couvent de Vallparadís en 1431 ; neanmoins, elle révéla la division qui existait dans l'Ordre à ce moment. La courte vie du couvent de Vallparadís avait été pleine de difficultés et conflits, mais son Etablissement Etait un pas important vers la reforme de l'Ordre de la part de ceux qui ne pouvaient pas oublier les origines érémitiques de l'Ordre.

\section{SUMMARY}

The foundation of the Carmelite house in Vallparadis, Terrassa in 1413 seems to have been an ill-fated altempt by some friars to retum to a more contemplative way of life. The only extant documents suggest that the venture was costly in a number of ways, causing ill-feeling between the friars at Terrassa and their superiors in the Province of Catalonia. The experiment only lasted until 1431, but it was indicative of the dichotomy which existed within the Order at that time. In brief, the short life of the house of Vallparadis was fraught with difficulty and conflict, but its establishment was a significant step towards reform by those who could not forget the eremitical origins of the Order. 